reduction of the diffuse scattering by the miniature pressure cell described below. On the triple-axis spectrometer, we achieved a high resolution in energy better than $50 \mu \mathrm{eV}$. For most of the work reported here, the spectrometer was used in an elastic mode where the initial wavevector was chosen as $k_{\mathrm{i}}=1.2 \AA$. Data were collected near the [110] lattice Bragg point. The spectrometer $4 \mathrm{~F} 1$ permits scans on a cartesian grid only, so that the transverse spread could only be studied in scans tangential $(\mathrm{T})$ to the sphere of intensity shown in Fig. 1 (see also Fig. 2 legend). The resolution function was determined at the [110] nuclear Bragg peak, and is marked in the plots as R. For the experiments, the miniature pressure cell was mounted on a so-called orange cryostat, for minimum temperatures of $1.6 \mathrm{~K}$. The data collected at the SANS spectrometer V4 reproduce the triple-axis data in the region of data overlap. We follow the usual convention where [..] denotes reciprocal lattice points, (..) a particular direction in reciprocal space and $\langle.$.$\rangle the$ family of all equivalent directions in reciprocal space.

\section{High-pressure techniques}

High pressures were generated with a miniature clamp cell (outer diameter $12 \mathrm{~mm}$ ) made of Cu:Be using standard PTFE sealing caps and Fluorinert as pressure transmitter. The diameter of the cylindrical samples was smaller than the inner diameter of the PTFE sealing caps by a few tenths of a millimetre. The samples were left floating free in the pressure medium to avoid the effects of differential contraction by a sample mount. Two pressure cells were prepared with a sample each, where the $\langle 110\rangle$ and $\langle 111\rangle$ axes were, respectively, parallel to the cylinder axis to save experiment time and to test for reproducibility. The lattice mosaic spread was found to be unchanged for both samples at all pressures studied. The pressure technique is identical to that used in a large number of studies of bulk properties of, for example, the resistivity, magnetization and quantum oscillatory phenomena, and was previously used in similar neutron diffraction studies ${ }^{30}$. None of these studies indicated any hints of non-hydrostatic pressure components. However, we observe a trend for the domains in the scattering plane to be populated most strongly, that is perpendicular to the vertical axis of the pressure cell. This may be a consequence of tiny non-hydrostatic components that freeze into the pressure transmitter that we were not able to detect in the lattice mosaic or lattice form factor. For the two pressure cells, the longitudinal and transverse spread described in the text is reproducibly the same, clearly establishing that the effects are intrinsic to the sample and not caused by any tiny non-hydrostaticities. The pressure was consistently determined from (1) the change of the lattice constant, (2) the superconducting transition of Sn and (3) the bulk magnetic transition measured in a vibrating sample magnetometer when $p<p_{c}$.

\section{Sample preparation and quality}

The single-crystal samples investigated here were grown by r.f. induction of zone-refined high-purity starting materials on a water-cooled $\mathrm{Cu}$-crucible in an ultrahigh-vacuum environment. The resulting ingots were annealed for 2 weeks near the melting point. Single-crystal samples were oriented by Laue X-ray diffraction, and cut by low-power spark erosion. The samples investigated have a tiny, resolution-limited mosaic spread $\eta \ll 0.2^{\circ}$, which compares with industrial quality silicon single crystals and is orders of magnitude smaller than typically found in intermetallic compounds. The very low value of $\eta$ underscores the exceptional intrinsic spread around $\langle 110\rangle$ of the magnetic state above $p_{c}$.

Received 30 September; accepted 14 November 2003; doi:10.1038/nature02232.

1. Chandra, P., Coleman, P., Mydosh, J. A. \& Tripathi, V. Hidden orbital order in the heavy fermion metal $\mathrm{URu}_{2} \mathrm{Si}_{2}$. Nature 417, 831-834 (2002).

2. Grosche, F. M. G. et al. Anomalous low temperature states in $\mathrm{CeNi}_{2} \mathrm{Ge}_{2}$ and $\mathrm{CePd}_{2} \mathrm{Si}_{2}$. J. Phys. Condens. Matter 12, L533-L540 (2000)

3. Dagotto, E., Hotta, T. \& Moreo, A. Colossal magnetoresistant materials: The key role of phase separation. Phys. Rep. 344, 1-153 (2001).

4. Kivelson, S. A. et al. How to detect fluctuating order in the high-temperature superconductors. Rev. Mod. Phys. 75, 1201-1241 (2003).

5. Sachdev, S. Order and quantum phase transitions in the cuprate superconductors. Rev. Mod. Phys. 75, 913-932 (2003)

6. Zaanen, J. et al. The geometric order of stripes and Luttinger liquids. Phil. Mag. B 81, 1485-1531 (2001).

7. Pfleiderer, C., Julian, S. R. \& Lonzarich, G. G. Non-Fermi liquid nature of the normal state of itinerant-electron ferromagnets. Nature 414, 427-430 (2001)

8. Pfleiderer, C. The non-Fermi liquid puzzle of MnSi at high pressure. Physica B 328, 100-104 (2003)

9. Doiron-Leyraud, N. et al. Fermi-liquid breakdown in the paramagnetic phase of a pure metal. Nature 425, 595-599 (2003)

10. Pfleiderer, C., McMullan, G. J., Julian, S. R. \& Lonzarich, G. G. Magnetic quantum phase transition in MnSi under hydrostatic pressure. Phys. Rev. B 55, 8330-8338 (1997).

11. Thessieu, C. et al. Field dependence of the magnetic quantum phase transition in MnSi. J. Phys. Condens. Matter 9, 6677-6687 (1997).

12. Koyama, K., Goto, T., Kanomata, T. \& Note, R. Observation of an itinerant metamagnetic transition in MnSi under high pressure. Phys. Rev. B 62, 986-991 (2000).

13. Barzykin, V. \& Gorkov, L. P. Possibility of nontrivial magnetic order by elastic neutron scattering. Phys. Rev. Lett. 70, 2479-2482 (1993)

14. Fawcett, E., Maita, J. P. \& Wernick, J. H. Magnetoelastic and thermal properties of MnSi. Int. J. Magn. 1, 29-34 (1970).

15. Bloch, D., Voiron, J., Jaccarino, V. \& Wernick, J. H. The high field-high pressure magnetic properties of MnSi. Phys. Lett. A 51, 259-291 (1975).

16. Ishikawa, Y. et al. Paramagnetic spin fluctuations in the weak itinerant-electron ferromagnet $\mathrm{MnSi}$. Phys. Rev. B 31, 5884-5893 (1985)

17. Yasuoka, H., Jaccarion, V., Sherwood, R. C. \& Wernick, J. H. NMR and susceptibility studies of MnSi

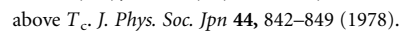

18. Taillefer, L., Lonzarich, G. G. \& Strange, P. The band magnetism of MnSi. J. Magn. Magn. Mater 54-57, 957-958 (1986)
19. Ishikawa, Y. \& Arai, M. Magnetic phase diagram of MnSi near critical temperature studied by neutron small angle scattering. J. Phys. Soc. Jpn 53, 2726-2733 (1984).

20. Lebech, B. in Recent Advances in Magnetism of Transition Metal Compounds (eds Kotani, A. \& Suzuki, N.) 167-178 (World Scientific, Singapore, 1993).

21. Mena, F. P. et al. Heavy carriers and non-Drude optical conductivity in MnSi. Phys. Rev. B 67, 241101(R) (2003).

22. Bak, P. \& Jensen, M. H. Theory of helical magnetic structures and phase transitions in MnSi and FeGe. J. Phys. C 13, L881-L885 (1980).

23. Nakanishi, O., Yanase, A., Hasegawa, A. \& Kataoka, M. The origin of the helical spin density wave in MnSi. Solid State Commun. 35, 995-998 (1980).

24. Thessieu, C. et al. Pressure effect on MnSi: An NMR study. J. Magn. Magn. Mater. 177-181, 609-610 (1998).

25. Lammert, P. E., Rokhsar, D. S. \& Toner, J. Topology and nematic ordering. Phys. Rev. Lett. 70, 1650-1653 (1993).

26. Wright, D. C. \& Mermin, N. D. Crystalline liquids: The blue phases. Rev. Mod. Phys. 61, 385-432 (1989)

27. Koistinen, E. P. \& Keyes, P. H. Light-scattering study of the structures of blue phase III. Phys. Rev. Lett. 74, 4460-4463 (1995)

28. Vonsovskij, S. V. Magnetism Vol. 2, Part 3 (Wiley, New York, 1974).

29. Mydosh, J. Spin Glasses: An Experimental Introduction (Taylor and Francis, London, 1993).

30. Huxley, A. et al. Co-existence of superconductivity and ferromagnetism in actinide compounds. J. Phys. Condens. Matter 15, S1945-S1956 (2003).

Acknowledgements We acknowledge discussions with P. Böni, A. N. Bogdanov, E. Dormann, B. Fåk, P. C. Howell, B. Keimer, B. Lebech, G. G. Lonzarich, I. Mazin, A. J. Millis, K.-H. Müller, J. Mydosh, J. Kübler, B. Rössli, S. Sachdev, S. S. Saxena, J. Schmalian, Q. Si, M. Turlakov, U. Rössler, M. Vojta, P. Wölfle and J. Zaanen. Help with the experiments from M. Uhlarz, B. Hennion, J. Haug, E. Garcia-Matres and the staff of the Laboratoire Léon Brillouin (Saclay) and the Hahn-Meitner Institut (Berlin), respectively, is also acknowledged. This work was supported by the Deutsche Forschungsgemeinschaft, the Helmholtz Gemeinschaft and the European Science Foundation under FERLIN.

Competing interests statement The authors declare that they have no competing financial interests.

Correspondence and requests for materials should be addressed to C.P. (Christian.Pfleiderer@physik.uni-karlsruhe.de).

\section{Observational evidence of a change in radiative forcing due to the indirect aerosol effect}

\author{
Joyce E. Penner ${ }^{1}$, Xiquan Dong ${ }^{2}$ \& Yang Chen ${ }^{1}$
}

${ }^{1}$ Department of Atmospheric, Oceanic, and Space Sciences, University of Michigan, Ann Arbor, Michigan 48109-2143, USA

${ }^{2}$ Department of Atmospheric Science, University of North Dakota, Grand Forks, North Dakota 58202-9006, USA

Anthropogenic aerosols enhance cloud reflectivity by increasing the number concentration of cloud droplets, leading to a cooling effect on climate known as the indirect aerosol effect. Observational support for this effect is based mainly on evidence that aerosol number concentrations are connected with droplet concentrations, but it has been difficult to determine the impact of these indirect effects on radiative forcing ${ }^{1-3}$. Here we provide observational evidence for a substantial alteration of radiative fluxes due to the indirect aerosol effect. We examine the effect of aerosols on cloud optical properties using measurements of aerosol and cloud properties at two North American sites that span polluted and clean conditions-a continental site in Oklahoma with high aerosol concentrations, and an Arctic site in Alaska with low aerosol concentrations. We determine the cloud optical depth required to fit the observed shortwave downward surface radiation. We then use a cloud parcel model to simulate the cloud optical depth from observed aerosol properties due to the indirect aerosol effect. From the good agreement between the simulated indirect aerosol effect and observed surface radiation, 
we conclude that the indirect aerosol effect has a significant influence on radiative fluxes.

The Southern Great Plains (SGP) site is centred at $36^{\circ} 37^{\prime} \mathrm{N}$, $97^{\circ} 30^{\prime} \mathrm{W}$, in Oklahoma, and is a typical continental site with high aerosol number concentration $\left(500-600 \mathrm{~cm}^{-3}\right.$ for particles with diameter between 0.1 and $10 \mu \mathrm{m}$, and $1,000-10,000 \mathrm{~cm}^{-3}$ for total condensation nuclei $(\mathrm{CN})$ concentration $^{4}$ ) and composition of mixed-continental origin. The North Slope of Alaska (NSA) site is located at $71^{\circ} 19^{\prime} \mathrm{N}, 156^{\circ} 37^{\prime} \mathrm{W}$, in Barrow, Alaska, and is a typical Arctic site with low aerosol concentration ( $\mathrm{CN}$ concentration of $99 \pm 120 \mathrm{~cm}^{-3}$ for our study) and composition determined partly by sea-salt particles (see Table 1). Here, these data and data from the Atmospheric Radiation Measurement (ARM) programme are used to examine the effects of aerosols on cloud radiative properties.

Dong et al. ${ }^{5}$ developed a method to derive cloud optical depth $\left(\tau_{\mathrm{c}}\right)$ by requiring that a delta-2-stream radiative transfer model match the observed downward broadband shortwave flux at the surface, and validated its use by comparison with in situ aircraft data ${ }^{6-9}$. Figure 1 shows the relationship between the derived $\tau_{\mathrm{c}}$ and the cloud liquid water path (LWP) at both the SGP and NSA sites. In this figure, the LWP is derived from microwave radiometer brightness temperatures at 23.8 and $31.4 \mathrm{GHz}$ using a statistical retrieval method $^{10}$, and the cloud optical depth is derived from the radiative transfer model and Eppley precision spectral pyranometer measurements at the ARM sites ${ }^{5,11}$. There is a significant difference in the slope of the relationship between cloud optical depth and LWP at these two sites. Below, we show that this difference can be explained by the indirect aerosol effect.

The time periods in this study were from 1 May to 30 September 2000 at the ARM NSA site, and from November 1996 to November 1998 at the ARM SGP site. During these two time periods the cloud temperatures at both sites are above $-13^{\circ} \mathrm{C}$ for most of the time, so that clouds at both sites can be viewed mostly as liquid-phase and liquid-dominant mixed-phase clouds.

We used a warm-cloud adiabatic parcel model ${ }^{12}$ to examine the effect of aerosols on cloud drop number concentration. The parcel model requires that we specify the aerosol size distribution, total number concentration, composition, and updraft velocity. Then, we estimated the cloud optical depth using the measured cloud properties (cloud geometric thickness and LWP). Cloud geometric thickness is the difference between the cloud top height (derived from millimetre cloud radar measurements) and the cloud base height (derived from laser ceilometer measurements ${ }^{5}$ ).

We established five criteria for choosing the clouds under which cloud properties can be estimated using the retrieval method. These are: (1) only single-layer and overcast low-level stratus clouds are present as determined from cloud radar observations, (2) the cosine of solar zenith angle $\left(\mu_{0}\right)$ is larger than $0.2,(3)$ the range of solar transmission is between 0.1 and 0.7, (4) LWP is between 20 and $600 \mathrm{~g} \mathrm{~m}^{-2}$, and (5) cloud top height is less than $3 \mathrm{~km}$. We identified approximately $300 \mathrm{~h}$ of the stratus clouds (more than 3,600 samples at 5-min resolution) that satisfied these five criteria at the NSA site and $500 \mathrm{~h}$ at the SGP site. In addition to these criteria, for examining the effects of aerosols on clouds we also required that the atmosphere be well mixed below cloud base and that the cloud top height

\begin{tabular}{|c|c|c|c|c|}
\hline \multicolumn{5}{|c|}{ Table 1 Average measured aerosol composition } \\
\hline & \multicolumn{2}{|c|}{ SGP site } & \multicolumn{2}{|c|}{ NSA site } \\
\hline & $\mu \mathrm{gm}^{-3}$ & Percentage & $\mu \mathrm{g} \mathrm{m}^{-3}$ & Percentage \\
\hline $\mathrm{NaCl}$ & 0.13 & 0.88 & 0.48 & 29.92 \\
\hline$\left(\mathrm{NH}_{4}\right)_{2} \mathrm{SO}_{4}$ & 4.36 & 29.10 & 0.54 & 33.28 \\
\hline Insoluble & 9.79 & 65.26 & 0.51 & 31.63 \\
\hline $\mathrm{NO}_{3}^{-}$ & 0.40 & 2.69 & 0.03 & 1.88 \\
\hline $\mathrm{K}^{+}$ & 0.10 & 0.63 & 0.01 & 0.57 \\
\hline $\mathrm{Mg}^{2+}$ & 0.03 & 0.17 & 0.02 & 1.49 \\
\hline $\mathrm{Ca}^{2+}$ & 0.19 & 1.25 & 0.02 & 1.21 \\
\hline
\end{tabular}

be less than $2.5 \mathrm{~km}$. These additional criteria reduced the number of cases for further analysis to 28 at the SGP site and 109 at the NSA site.

The criterion of a well-mixed atmosphere below cloud base enabled us to calculate the aerosol number concentration at cloud base by using the measured surface concentrations assuming that the aerosol mixing ratio is constant with altitude ${ }^{13}$. This criterion was satisfied by requiring that the water vapour mixing ratio measured by the ARM rawinsonde sounding near the cloud base and that near the surface were within $\pm 15 \%$. Rawinsonde data are available for each day near local noon.

The cloud droplet number concentration was calculated from the adiabatic cloud parcel model using the measured aerosol ion composition and total mass at both sites (available approximately daily at each site; ref. 14 and P. K. Quinn, personal communication) as well as the $\mathrm{CN}$ number concentration available from NOAA Climate Monitoring and Diagnostics Laboratory measurements ${ }^{15}$. No direct measurements of aerosol size distribution were available. However, typical continental and marine size distributions are available from a number of measurements (see Table 5.1 in ref. 1). Moreover, for the SGP site, ARM provided measurements of the total aerosol concentration with diameter $>0.1 \mu \mathrm{m}$. So we developed a 2-mode lognormal size distribution that fitted both the total $\mathrm{CN}$ concentrations and the number concentration with diameter
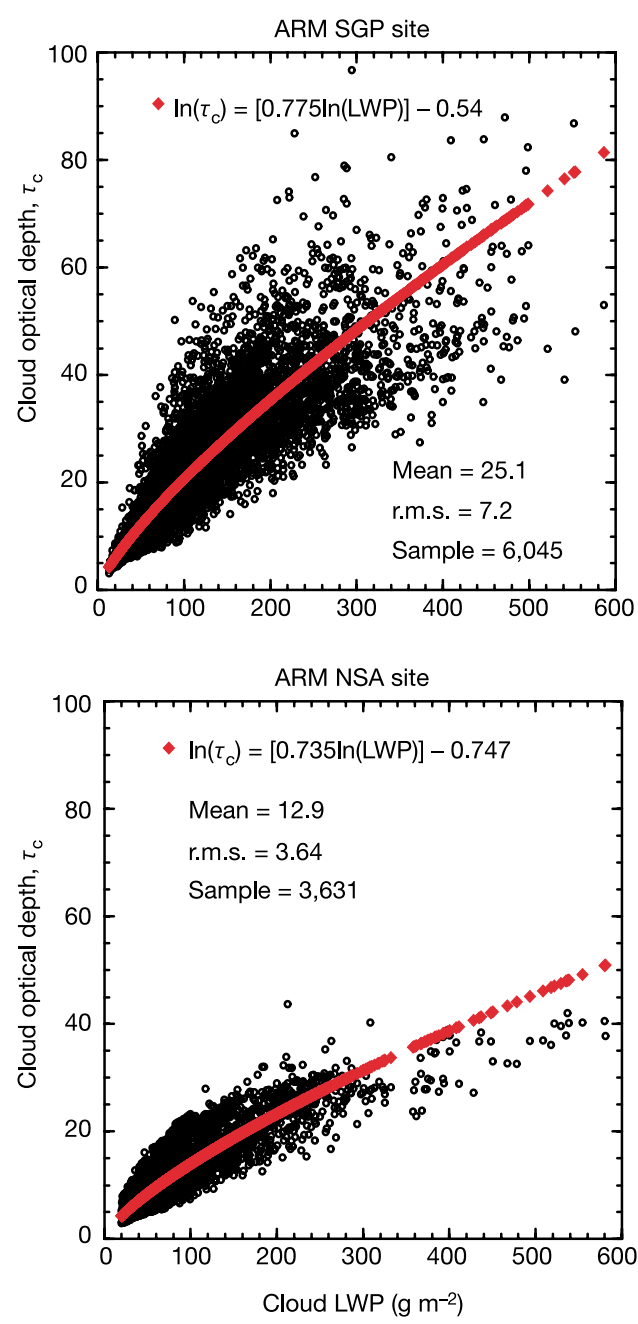

Figure 1 Cloud optical depth, as determined from the observed shortwave flux, plotted against LWP. The cloud optical depth was determined by requiring that a delta-2-stream radiative transfer model fit the observed ground level broadband shortwave radiative flux. 
$>0.1 \mu \mathrm{m}$. We assumed that mode 1 had a mean diameter equal to $0.02 \mu \mathrm{m}$ and a geometric standard deviation of 1.1, while mode 2 had a mean diameter of $0.08 \mu \mathrm{m}$ and a geometric standard deviation of 1.75. For the NSA site, based on aerosol composition, we initially used either a typical marine size distribution ${ }^{1}$ (a single-mode lognormal size distribution with a mean diameter equal to $0.19 \mu \mathrm{m}$ and a geometric standard deviation of 1.5) or a typical continental size distribution ${ }^{1}$. For these size distributions and the measured composition, a fit to the standard relationship ${ }^{16}$ for cloud condensation nuclei $(\mathrm{CCN})$ as a function of supersaturation $(S)$, $\mathrm{CCN}=c S^{k}$, yields $c=371 \pm 172$ and $k=0.39 \pm 0.11$ for the SGP site, and $k=0.31 \pm 0.31$ for the NSA site ( $c$ was not computed for the NSA site because almost all aerosols are activated at this site). We estimated the vertical velocity for each time period based on the average updraft velocity and the turbulent kinetic energy (TKE) from the Model Output Location Time Series data provided by the National Centers for Environmental Prediction ${ }^{17}$ using $w=\bar{w}+$ $c \sqrt{\mathrm{TKE}}$, where $c=0.7$ (ref. 18). The modelled cloud optical depth is not sensitive to updraft at the NSA site, and would be very similar at the SGP site had we used the maximum millimetre cloud radar
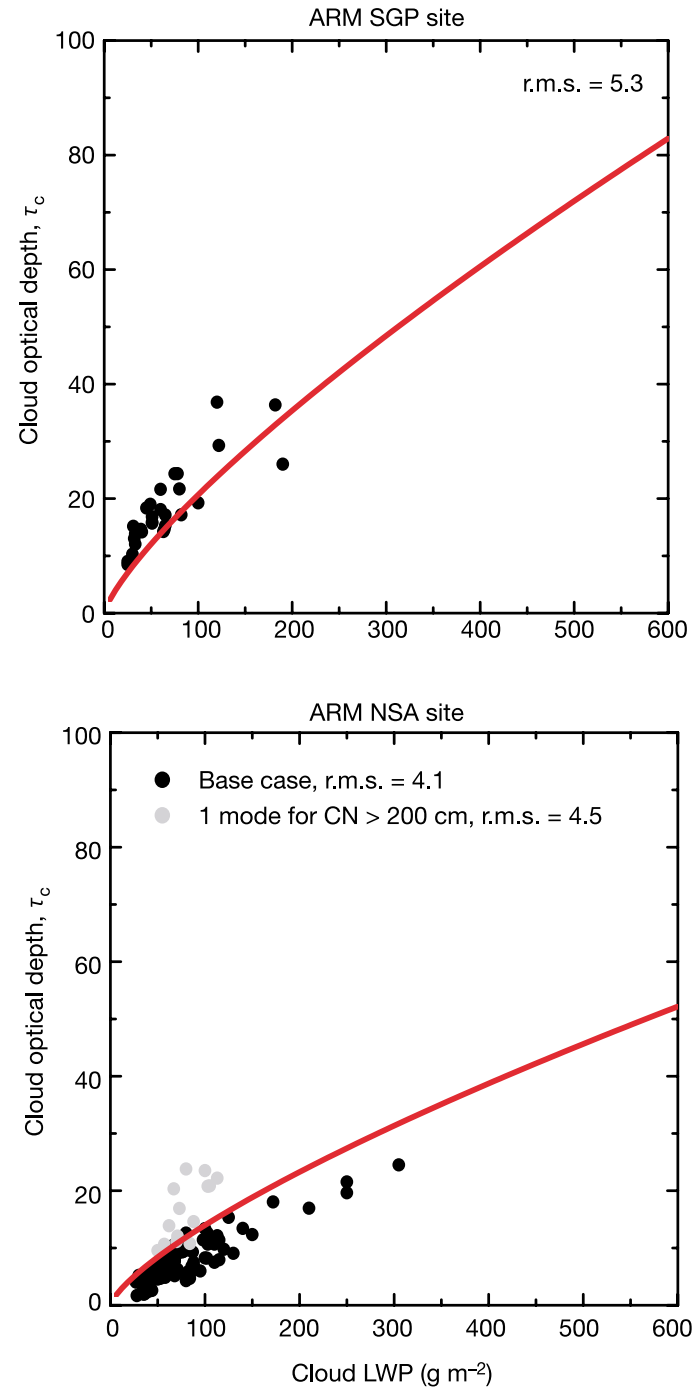

Figure 2 Cloud optical depth, as determined from the parcel model, plotted against LWP. Cloud optical depth was determined using the predicted droplet number concentrations from an adiabatic cloud parcel model and the measured aerosol concentrations and composition. In both Figs 1 and 2, the cloud LWP was that determined from the microwave radiometer measurement.
Doppler values for the updraft velocity.

Because the liquid water content within adiabatic stratiform clouds generally increases linearly with height, given the droplet number concentration $N$ and LWP, the cloud optical depth can be calculated from $\tau_{\mathrm{c}}=1.765(k \pi)^{1 / 3} N^{1 / 3} \rho_{w}^{-2 / 3} C_{w}^{-1 / 6} \mathrm{LWP}^{5 / 6}$, where $\rho_{\mathrm{w}}$ is the liquid water density, $C_{\mathrm{w}}=2 \mathrm{LWP} / \mathrm{H}^{2}, H$ is the cloud geometrical thickness, and $k$ is a parameter that describes the dispersion of the cloud drops ${ }^{19}$. The $\mathrm{CN}$ data used in the model simulation, as well as cloud base and cloud top, and LWP, were averaged over a $1 \mathrm{~h}$ time period. We used $k=\left[\left(5.0 \times 10^{-4} N\right)+1.18\right]^{-3}$, based on a fit to observations ${ }^{20}$.

Figure 2 shows the cloud optical depth and LWP relationship found here using the parcel model. The line in each curve shows the relationship found in Fig. 1 needed to match the observed surface shortwave broadband flux. The points shown by the grey dots at the NSA site have CN number concentration greater than $200 \mathrm{~cm}^{-3}$ and used the original single-mode size distribution. Because it is likely that higher $\mathrm{CN}$ number concentrations are indicative of the presence of a nucleation mode in the size distribution, we added a small lognormal mode (as used at the SGP site) to the single-mode distribution at the NSA site for these points (with the average ratio between the large and small modes that was found at the SGP site). The adjustment of size distribution to the 2-mode distribution improves the fit between the parcel model results for cloud optical depth and that required to fit the shortwave broadband flux.

The large spread in the derived cloud optical depth from surface radiation measurements shown in Fig. 1 can result from effects that are not taken into account in the parcel model: entrainment, drizzle formation, and ice formation and splintering. But could any of these processes contribute to a difference in the observed slope between the two sites? Entrainment could potentially both increase and decrease the slope of the optical depth versus LWP relationship, but if it decreases the liquid water content by half at the top of the cloud it would not have a large impact at either site. The presence of ice particles at the NSA site does not greatly affect either the retrieved $\mathrm{LWP}^{21}$ or retrieved optical depths ${ }^{7}$. Preferential drizzle at the NSA site should not greatly affect the retrieved optical depth if it is less than $25 \%$ of the total LWP. The fact that warm-cloud adiabatic microphysics explains the retrieved cloud optical depth supports this assumption.

Our study shows that the cloud optical depth required to fit the surface downward shortwave flux at both the SGP and NSA sites can

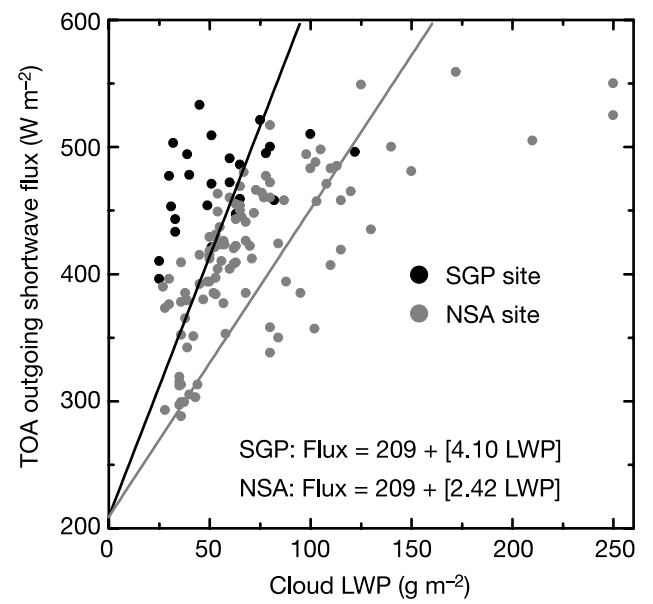

Figure 3 Modelled outgoing shortwave radiation at the SGP and NSA sites using the average albedo and zenith angle from the SGP site and the cloud properties from the adiabatic model. Only points with $\tau_{\mathrm{c}}<25$ are shown. If the anthropogenic aerosol composition at the SGP site from ref. 23 is used to determine the cloud drop concentration in the adiabatic model, then the average radiative forcing at the SGP site for these cases is $10.2 \mathrm{~W} \mathrm{~m}^{-2}$. TOA, top of atmosphere. 
be explained by the indirect aerosol cloud effect. The use of a parcel model to determine the cloud droplet number concentration enables us to separate the effects of the cloud LWP and cloud droplet number concentration on the cloud optical depth. An examination of the TOA shortwave flux from the radiative transfer model applied to the two sites does not directly confirm the indirect effect, because the observed surface albedos at the NSA site for our cases $(0.6 \pm 0.28)$ are significantly larger than those from the SGP site $(0.2 \pm 0.02)$. However, the model can be used to estimate the outgoing flux difference if the clouds from the NSA site had the same average surface albedo and average zenith angle as those from the SGP site (see Fig. 3). This analysis indicates that these sites provide important evidence corroborating the effect of aerosols on cloud optical properties and on shortwave fluxes at both the surface and the TOA. Moreover, the analysis indicates that a parameterization of the effects of aerosols on clouds on the basis of an adiabatic parcel model and average aerosol size distributions such as those used in current general circulation models ${ }^{18,22,23}$ provides a good estimate of cloud optical properties determined over a broad range of aerosol concentrations.

Received 28 May; accepted 17 November 2003; doi:10.1038/nature02234.

1. Penner, J. E. et al. in Climate Change 2001: The Scientific Basis (eds Houghton, J. T. et al.) 289-348 (Cambridge Univ. Press, Cambridge, UK, 2001)

2. Rosenfeld, D. \& Feingold, G. Explanation of discrepancies among satellite observations of the aerosol indirect effects. Geophys. Res. Lett. 30, doi:10.1029/2003GL017684 (2003).

3. Brenguier, J.-L., Pawlowska, H. \& Schüller, L. J. Cloud microphysical and radiative properties for parameterization and satellite monitoring of the indirect effect of aerosol on climate. J. Geophys. Res. 108, doi:101029/2002JD002682 (2003)

4. Sheridan, P. J., Delene, D. J. \& Ogren, J. A. Four years of continuous surface aerosol measurements from the Department of Energy's Atmospheric Radiation measurement Program Southern Great Plains Cloud and Radiation Testbed site. J. Geophys. Res. 106, 20735-20747 (2001).

. Dong, X., Ackerman, T. P., Clothiaux, E. E., Pilewskie, P. \& Han, Y. Microphysical and radiative properties of stratiform clouds deduced from ground-based measurements. J. Geophys. Res. 102, 23829-23843 (1997).

6. Dong, X., Ackerman, T. P. \& Clothiaux, E. E. Parameterizations of microphysical and shortwave radiative properties of boundary layer stratus from ground-based measurements. J. Geophys. Res. 102, 31681-31393 (1998)

7. Dong, X., Mace, G. G., Minnis, P. \& Young, D. F. Arctic stratus cloud properties and their effect on the surface radiation budget: selected cases from FIRE ACE. J. Geophys. Res. 106, 15297-15312 (2001).

8. Dong, X. et al. Comparison of stratus cloud properties deduced from surface, GOES, and aircraft data during the March 2000 ARM Cloud IOP. J. Atmos. Sci. 59, 3265-3284 (2002).

9. Dong, X. \& Mace, G. G. Profiles of low-level stratus cloud microphysics deduced from ground-based measurements. J. Atmos. Ocean. Tech. 20, 42-53 (2003).

10. Liljegren, J. C., Clothiaux, E. E., Mace, G. G., Kato, S. \& Dong, X. A new retrieval for liquid water path using a ground based microwave radiometer and measurements of cloud temperature. J. Geophys. Res. 106, 14485-14500 (2001).

11. Dong, X. \& Mace, G. G. Arctic stratus cloud properties and radiative forcing derived from groundbased data collected at Barrow Alaska. J. Clim. 16, 445-461 (2003).

12. Liu, X. \& Seidl, W. Modeling study of cloud droplet nucleation and in-cloud sulfate production during the Sanitation of the Atmosphere (SANA) 2 campaign. J. Geophys. Res. 103, 16145-16158 (1998).

13. Delene, D. J. \& Deshler, T. Vertical profiles of cloud condensation nuclei above Wyoming. J. Geophys. Res. 106, 12579-12588 (2001)

14. Quinn, P. K. et al. A three-year record of simultaneously measured aerosol chemical and optical properties at Barrow, Alaska. J. Geophys. Res. D 107, doi:101029/2001JD001248 (2002)

15. Climate Modeling and Diagnostics Laboratory data archive 〈http://www.cmdl.noaa.gov/info/ ftpdata.html> (2000).

16. Twomey, S. The nuclei of natural clouds formation. Part II: The supersaturation in natural clouds and the variation of cloud droplet concentration. Geofis. Pura Appl. 43, 243-249 (1959).

17. Rogers, E., Deaven, D. G. \& DiMego, G. J. The regional analysis system for the operational "early" eta model: original 80-km configuration and recent changes. Weath. Forecast. 10, 810-825 (1995).

18. Lohmann, U., Feichter, J., Chuang, C. C. \& Penner, J. E. Prediction of the number of cloud droplets in the ECHAM GCM. J. Geophys. Res. 104, 9169-9198 (1999).

19. Brenguier, J.-L. et al. Radiative properties of boundary layer clouds: droplet effective radius versus number concentration. J. Atmos. Sci. 57, 803-821 (2000).

20. Liu, Y. \& Daum, P. H. Indirect warming effect from dispersion forcing. Nature 419, 580-581 (2002).

21. Lin, B., Wielicki, B., Minnis, P. \& Rossow, W. Estimation of water cloud properties from satellite microwave, infrared, and visible measurements in oceanic environments. 1, Microwave brightness temperature simulations. J. Geophys. Res. 103, 3873-3886 (1998).

22. Ghan, S. J., Easter, R. C., Hudson, J. \& Breon, F.-M. Evaluation of aerosol indirect radiative forcing in MIRAGE. J. Geophys. Res. 106, 5317-5334 (2001).

23. Chuang, C. C. et al. Cloud susceptibility and the first aerosol indirect forcing: Sensitivity to black carbon and aerosol concentrations. J. Geophys. Res. D 107, doi:101029/2000JD000215 (2002).
Acknowledgements We thank P. Quinn for providing the composition data at the ARM SGP and NSA sites. During this study, X.D. was also supported by the NASA CERES project. This work was supported by the DOE ARM programme.

Competing interests statement The authors declare that they have no competing financial interests.

Correspondence and requests for materials should be addressed to J.E.P. (penner@umich.edu).

\section{Tungsten isotope evidence that mantle plumes contain no contribution from the Earth's core}

Anders Scherstén ${ }^{1}$, Tim Elliott ${ }^{1}$, Chris Hawkesworth ${ }^{1}$ \& Marc Norman $^{2}$

${ }^{1}$ Department of Earth Sciences, University of Bristol, Will's Memorial Building, Queen's Road, Bristol BS8 1RJ, UK

${ }^{2}$ Research School of Earth Sciences, The Australian National University, Canberra, Australian Capital Territory 0200, Australia

Osmium isotope ratios provide important constraints on the sources of ocean-island basalts, but two very different models have been put forward to explain such data. One model interprets ${ }^{187}$ Os-enrichments in terms of a component of recycled oceanic crust within the source material ${ }^{1,2}$. The other model infers that interaction of the mantle with the Earth's outer core produces the isotope anomalies and, as a result of coupled ${ }^{186} \mathrm{Os}-{ }^{187} \mathrm{Os}$ anomalies, put time constraints on inner-core formation ${ }^{3-5}$. Like osmium, tungsten is a siderophile ('iron-loving') element that preferentially partitioned into the Earth's core during core formation but is also 'incompatible' during mantle melting (it preferentially enters the melt phase), which makes it further depleted in the mantle. Tungsten should therefore be a sensitive tracer of core contributions in the source of mantle melts. Here we present high-precision tungsten isotope data from the same set of Hawaiian rocks used to establish the previously interpreted ${ }^{186} \mathrm{Os}-{ }^{187} \mathrm{Os}$ anomalies and on selected South African rocks, which have also been proposed to contain a core contribution ${ }^{6}$. None of the samples that we have analysed have a negative tungsten isotope value, as predicted from the core-contribution model. This rules out a simple core-mantle mixing scenario and suggests that the radiogenic osmium in ocean-island basalts can better be explained by the source of such basalts containing a component of recycled crust.

Many ocean-island basalts are thought to be the surface expression of mantle plumes that originate from a boundary layer within the mantle. Ocean-island basalts are geochemically distinct from mid-ocean-ridge basalts, and the differences are often attributed to recycled components of crust or ancient melt-depleted lithosphere $\mathrm{e}^{7,8}$. It has been argued that the Re-Os system provides powerful evidence for recycled components because Re/Os ratios are high in melts and correspondingly low in residues, which with time develop increasingly radiogenic and depleted Os-isotope compositions respectively ${ }^{1,2,9,10}$. Yet $\mathrm{Re}-\mathrm{Os}$ is also fractionated by inner-core crystallization, where Os partitions into the inner core leaving the outer core with a high Re/Os ratio. Thus, small core contributions are an alternative explanation for the occurrence of radiogenic Os in ocean-island basalts ${ }^{11}$.

In principle, such core contributions can be tested using combined ${ }^{186} \mathrm{Os}-{ }^{187} \mathrm{Os}$ isotopes, because Pt-Os fractionates in the same way as Re-Os during inner-core crystallization and ${ }^{190} \mathrm{Pt}$ decays to ${ }^{186}$ Os. In view of the long half-lives of ${ }^{190} \mathrm{Pt}\left(T_{1 / 2} \approx 450 \mathrm{Gyr}\right)$ and 